\title{
Contrasting patterns and drivers of soil bacterial and fungal diversity across a mountain gradient
}

Running title: microbial elevational diversity patterns

Authors: Congcong Shen ${ }^{1,2 \#}$, Anna Gunina ${ }^{3 \#}$, Yu Luo ${ }^{4 *}$, Jianjun Wang ${ }^{2,5}$, Ji-Zheng $\mathrm{He}^{1,2}$, Yakov Kuzyakov ${ }^{3,6,7}$, Andreas Hemp ${ }^{8}$, Aimée T. Classen ${ }^{9,10}$, Yuan Ge $\mathrm{e}^{1,2^{*}}$

1 State Key Laboratory of Urban and Regional Ecology, Research Center for Eco-Environmental Sciences, Chinese Academy of Sciences, Beijing 100085, China

2 University of Chinese Academy of Sciences, Beijing 100049, China

3 Department of Environmental Chemistry, University of Kassel, Nordbahnhof Strasse 1a, Witzenhausen 32213, Germany

4 Institute of Soil and Water Resources and Environmental Science, Zhejiang Provincial Key Laboratory of Agricultural Resources and Environment, Zhejiang University, Hangzhou 310058, China

5 State Key Laboratory of Lake Science and Environment, Nanjing Institute of Geography and Limnology, Chinese Academy of Sciences, Nanjing 210008, China

6 Department of Soil Science of Temperate Ecosystems, Department of Agricultural Soil Science, University of Goettingen, Göttingen 37077, Germany

7 Institute of Environmental Sciences, Kazan Federal University, 420049 Kazan, Agro-Technological Institute, RUDN University, Moscow 117198, Russia

This is the author manuscript accepted for publication and has undergone full peer review but has not been through the copyediting, typesetting, pagination and proofreading process, which may lead to differences between this version and the Version of Record. Please cite this article as doi: 10.1111/1462-2920.15090

This article is protected by copyright. All rights reserved. 
8 Department of Plant Systematics, University of Bayreuth, Universitätsstraße 30, Bayreuth 95440, Germany

9 Rubenstein School of Environment and Natural Resources, University of Vermont, Burlington, Vermont 05405, USA

10 Gund Institute for Environment, University of Vermont, Burlington, VT, USA

\# These authors contributed equally to this work.

\section{${ }^{*}$ Corresponding author:}

Yu Luo

Tel.: +86 057188982779; Email: luoyu@zju.edu.cn

Yuan Ge

Tel.: +86 1062913536; E-mail: yuange@rcees.ac.cn 


\section{Originality-Significance Statement}

This paper is the first study in examining soil microbial diversity and community compositions on Mt. Kilimanjaro, which is a substantial contribution by filling the knowledge gap regarding this rarely/hardly touched, but important region. Our results showed the contrasting patterns and drivers of soil bacterial and fungal diversity across a broad elevation gradient of a range of $3400 \mathrm{~m}$ on Mt. Kilimanjaro. The diversity patterns and drivers of those diversity patterns differ among taxonomic groups (phyla/classes) within bacterial or fungal communities. Our study demonstrated that bacterial and fungal diversity and community composition responded differently to climate and edaphic properties along an extensive mountain gradient and suggest that the elevational diversity patterns across microbial groups are determined by distinct environmental variables. These novel findings will add important knowledge for regional-scale species distributions, as well as microbial responses to climate change in montane ecosystems. 


\section{Summary}

Microbial elevational diversity patterns have been extensively studied, but their shaping mechanisms remain to be explored. Here, we examined soil bacterial and fungal diversity and community compositions across a $3.4 \mathrm{~km}$ elevational gradient (consists of 5 elevations) on Mt. Kilimanjaro located in East Africa. Bacteria and fungi had different diversity patterns across this extensive mountain gradient bacterial diversity had a $U$ shaped pattern while fungal diversity monotonically decreased. Random forest analysis revealed that $\mathrm{pH}$ (12.61\% importance) was the most important factor affecting bacterial diversity, whereas mean annual temperature (9.84\% importance) had the largest impact on fungal diversity, which was consistent with results obtained from mixed-effects model. Meanwhile, the diversity patterns and drivers of those diversity patterns differ among taxonomic groups (phyla/classes) within bacterial or fungal communities. Taken together, our study demonstrated that bacterial and fungal diversity and community composition responded differently to climate and edaphic properties along an extensive mountain gradient, and suggest that the elevational diversity patterns across microbial groups are determined by distinct environmental variables. These findings enhanced our understanding of the formation and maintenance of microbial diversity along elevation, as well as microbial responses to climate change in montane ecosystems. 


\section{Introduction}

Ecologists have been searching for generalizable patterns describing biodiversity for 100's of years and observations along elevational gradients have been key in shaping debates about how biodiversity responds to climate (Rahbek, 1995; Lomolino, 2001; Martiny et al., 2006). In fact, elevational species diversity patterns for plants and animals have been studied for two centuries, and related hypotheses (e.g., climate, mid-domain effect) have been proposed to explain general patterns along gradients (e.g., decreasing, unimodal) (Rahbek, 2005; McCain, 2009). In spite of their high abundance and vital roles in ecosystem functioning, until recently, microorganisms have been left out of in these analyses because their abundance and composition was difficult to observe and measure (but see, Bryant et al., 2008; Singh et al., 2012; Shen et al., 2014; Peay et al., 2017; Hendershot et al., 2017; Nottingham et al., 2018).

Microbial responses to elevational gradients remain mixed. Some studies found that soil bacteria showed decreasing diversity patterns (Bryant et al., 2008; Wang et al., 2015; Nottingham et al., 2018; Shen et al., 2019). For example, one of the earliest studies reported that the diversity of soil Acidobacteria monotonically decreased with the increasing elevation (Bryant et al., 2008). Some studies found hump-shaped or U-shaped diversity patterns for soil bacteria (Singh et al., 2012; Li et al., 2016; Peay et al., 2017). There were also studies showing that soil bacterial diversity did not vary with elevation (Fierer et al., 2011; Shen et al., 2013; Singh et al., 2014). Nonetheless, the lack of a discernable trend in microbial diversity with elevation across studies may be the result of compounding effects of multiple environmental factors or undetected 
factors that are relevant to microbes, as well as the possibility that microbial diversity may not vary on a spatial scale that corresponds in any way to elevational gradients.

There are likely different elevational diversity patterns across microbial groups at multiple taxonomic levels. For example, one study on the Kohala Volcano of Hawai'i found contrasting diversity patterns with a hump-shaped diversity-elevation trend for bacteria and an increased diversity-elevation trend for fungi (Peay et al., 2017). While within bacterial communities, one study on Fuji Mountain found a decreasing diversity pattern for Acidobacteria and a hump-shaped diversity pattern for Proteobacteria, while actinobacterial diversity did not show any pattern with elevation (Singh et al., 2012). Given phyla or classes possess unique phylogenetic and ecological traits (e.g., r-strategy and k-strategy), an in-depth analysis of specific phyla or classes may help to inform hypotheses about why variance in diversity patterns emerges (Fierer et al., 2007).

There are two main scale-dependent categories of environmental factors that likely impact soil microbial diversity patterns along elevational gradients: (1) regional-scale factors such as climate, area, parent material, historical impacts (evolutionary constraints), plant productivity (Gaston, 2000); and (2) local-scale abiotic factors including $\mathrm{pH}$ and nutrients availability, and biotic interactions (e.g. mutualism and competition). Some studies suggest regional-scale climate factors (particular temperature) could strongly affect soil microbial diversity and community composition along elevational gradients (Singh et al., 2014; Ding et al., 2015; Nottingham et al., 2018), whereas others suggest the elevational microbial diversity 
patterns are determined by local-scale variation in soil pH (Shen et al., 2013; Geml et al., 2014; Wang et al., 2015; Peay et al., 2017). However, the relative importance of these hierarchical environmental factors in shaping soil biodiversity along elevation gradient remains less evaluated.

Theories have been proposed to explain the relationship between environmental factors and species diversity. For example, the mid-domain effect, assuming that spatial boundaries cause more overlap of species' ranges towards the centre of an area, has been widely used to explain the unimodal diversity pattern with elevation (Colwell et al., 2004; McCain, 2004; Miyamoto et al., 2014). Temperature has been shown positively correlate with species richness for macroorganisms (Hawkins et al., 2003; Evans et al., 2005) and microorganisms (Furhman et al., 2008; Zhou et al., 2016) in large-scale diversity patterns. The positive temperature-diversity relationship was commonly explained by the metabolic theory of ecology, which predicts changes of organisms' diversity along temperature gradients via biochemical kinetics of metabolism (Brown et al., 2004). The metabolic theory predictions have been specifically applied to microorganisms in horizontal and elevational investigations (Zhou et al., 2016; Nottingham et al., 2018). Species diversity often increases with increasing available energy, which is termed species-energy theory (Wright, 1983). This theory was widely accepted for plants and animals (Hawkins et al., 2003; Phillips et al., 2010). However, its applicability to soil communities has been less explored, although there is some evidence it holds for fungal functional guilds in wood and leaf environments (Schmit et al., 2005; Yang et al., 2016). 
Mt. Kilimanjaro, the highest free-standing mountain on earth, has a distinct vertical distribution of vegetations that extends from tropical to frozen zones. This extensive gradient mirrors the latitudinal vegetation gradient in the northern hemisphere and thus provides us with an excellent laboratory to study microbial distribution patterns at a regional scale (Hemp, 2006). Previous studies showed that the species richness of plants and animals significantly decreased with increasing elevation on Mt. Kilimanjaro (Hemp, 2006; Peters et al., 2016). Here, we measured soil bacterial and fungal communities along an elevation gradient (3.4 km elevation gradient, consists of 5 elevations) on Mt. Kilimanjaro. We used this gradient to test the following hypotheses: (1) Soil bacteria and fungi will have unique elevational diversity patterns, but different environmental drivers will be correlated with those patterns. (2) Fungal diversity will be positively related to plant productivity, as predicted by species-energy theory and recent findings which showed a significant relationship between them (Hiiesalu et al., 2017; Yang et al., 2017). (3) The composition of bacterial and fungal communities differed with elevation. Based on recent findings of global topsoil microbial studies by Bahram and colleagues (2018), bacterial community composition will be related to local soil conditions such as $\mathrm{pH}$, whereas fungal community composition will be related to larger scale processes, such as climate and plant productivity.

\section{Results}

Contrasting patterns with elevation: U-shaped for bacterial diversity, decreasing for 
fungal diversity

For richness, evenness and Shannon diversity metrics, the whole bacterial community showed a significant $\left(\mathrm{r}^{2}=0.721, p<0.001\right)$ U-shaped pattern, whereas the whole fungal community significantly $\left(r^{2}=0.404, p<0.001\right)$ decreased with elevation (Fig. 1a, Fig. 1b). Spearman correlation analysis showed that richness and evenness of the whole bacterial and fungal community were significantly $(p<0.01)$ correlated with Shannon index, with evenness having a higher coefficient with Shannon index (Fig. S1). For bacterial specific phyla, the diversity of nine phyla exhibited significant $(p<0.05)$ elevational patterns, with a U-shaped diversity pattern for Acidobacteria, Actinobacteria, Alphaproteobacteria, Gammaproteobacteria, an increasing diversity pattern for Gemmatimonadetes, Verrucomicrobia, Betaproteobacteria, Deltaproteobacteria, and a hump-shaped diversity pattern for Chloroflexi (Fig. S3). For fungal specific phyla and classes, the diversity of three phyla and eight classes exhibited significant $(p<0.05)$ elevational patterns, with a decreasing diversity pattern for Ascomycota, Archaeorhizomycetes, Pezizomycetes, Saccharomycetes, Tremellomycetes, a hump-shaped diversity patterns for Glomeromycota, Dothideomycetes, Leotiomycetes, Sordariomycetes, Agaricomycetes, and a U-shaped diversity pattern for Chytridiomycota (Fig. S4).

\section{Contrasting drivers: $\mathrm{pH}$ for bacterial diversity, MAT for fungal diversity}

In terms of Shannon index, bacterial and fungal diversity were linked with environmental factors. Random forest analysis found that $\mathrm{pH}(12.61 \%)$ was the most 
important factor affecting bacterial diversity, whereas MAT (9.84\%) had the largest impact on fungal diversity (Fig. 1c, Fig. 1d). This result was consistent with results obtained from mixed-effects model (Table 2). According to random forest analysis, MAP (11.35\%) and $\mathrm{pH}$ (7.98\%) were the second important factor for predicting bacterial and fungal diversity, respectively. Classified by climate, energy and local factors, random forest analysis showed a more important role of local factors in explanation of bacterial diversity, whereas climate factors shape fungal diversity (Fig. 1c, Fig. 1d). For bacterial specific phyla, the diversity of 10 phyla showed significant $(p<0.05)$ relationships with $\mathrm{pH}$. For fungal specific phyla and classes, the diversity of three phyla and seven classes exhibited significant $(p<0.05)$ relationships with MAT (Fig. S5).

\section{Effect of elevation on bacterial and fungal compositional dissimilarities}

The composition of bacterial and fungal communities differed with elevation according to PCoA plots based on Bray-Curtis distance (Fig. 2c, Fig. 2d). Permutational multivariate analysis of variance (PERMANOVA) showed that the compositional dissimilarities among elevations were significant ( $p<0.05$; Table S3). Dissimilarity of bacterial and fungal communities significantly $(p<0.001)$ and exponentially increased with increasing elevation distance (Fig. 2a, Fig. 2b). Specifically, the relative abundance of 10 bacterial phyla Alphaproteobacteria, Armatimonadetes, Bacteroidetes, Betaproteobacteria, Chlorobi, Chloroflexi, Cyanobacteria, Gammaproteobacteria, Elusimicrobia and Fibrobacteres significantly 
increased with increasing elevation (Fig. S6, Fig. S7, Table S5). For fungi, increased elevation was associated with increased dominance of Archaeorhizomycetes, Leotiomycetes, Tremellomycetes, and decreased dominance of Agaricomycetes, Blastocladiomycetes, Eurotiomycetes, Geoglossomycetes, Microbotryomycetes, Orbiliomycetes, Pucciniomycetes, Saccharomycetes, Ustilaginomycetes, Wallemiomycetes (Table S5). The beta diversity decomposition analyses showed that bacterial and fungal community compositional dissimilarities among all study sites were dominated by species replacement processes (contributed $80.24 \%$ and $74.17 \%$ for bacterial and fungal beta diversity, respectively), while richness difference processes only contributed $19.76 \%$ and $25.83 \%$ on average (Fig. 3a, Fig. 3b). Also, relative contribution of richness difference processes was lower (averagely 15.59\% and $21.90 \%$ for bacterial and fungal beta diversity, respectively) for beta diversity among sites within elevation (Fig. 3c, Fig. 3d).

\section{Linkages of bacterial and fungal community composition with environmental factors}

Of all the environmental factors examined, $\mathrm{pH}$ showed the highest correlation with bacterial community composition ( $\rho=0.759, p=0.001$ ), whereas MAT was most significantly correlated with fungal community composition $(\rho=0.582, p=$ 0.001) as determined by partial Mantel tests (Table S4). For bacterial community composition, five significant variables $-\mathrm{pH}$, MAT, TC, MAP and C/N explained $88.02 \%$ of the total variation $(p<0.05)$, with $\mathrm{pH}$ providing the greatest explanatory power (42.98\% of the total variation). Most of the variation, $65.75 \%$, in fungal 
community composition was explained by MAT, MAP, TN, and TC $(p<0.05)$ and MAT explained the largest percentage, $24.25 \%$ of the total variation (Table 3). For specific phyla and classes, the relative abundance of 11 bacterial phyla showed significant $(p<0.05)$ correlations with $\mathrm{pH}$, and the relative abundance of 13 fungal classes were significantly $(p<0.05)$ correlated with MAT (Fig. 5a, Fig. 5b, Table S5). Variation partitioning analysis showed that the joint effects of climate and local factors accounted for the largest explanation for variance of both bacterial and fungal community composition, whereas the pure effects of climate, energy and local were small (Fig. 4c, Fig. 4d).

\section{Predicted functional groups of bacteria and fungi}

Across all the sampling sites, dominant bacterial functional groups included groups that were involved into chemoheterotrophy, cellulolysis, nitrogen fixation and nitrification (Fig. S8). Dominant fungal functional groups included groups that were involved into wood saprotroph, soil saprotroph, dung saprotroph, plant pathogen, ectomycorrhizal and arbuscular mycorrhizal (Fig. S9). The effects of elevation on the diversity of eight fungal functional groups were tested, with a decreasing diversity pattern for animal pathogens, fungal parasites, and a hump-shaped pattern for arbuscular mycorrhiza, endophytes, saprotrophs being found, while others including ectomycorrhizal, lichenized and plant pathogen showed no apparent diversity pattern with elevation (Fig. S10). The relative abundance of 21 predicted bacterial functional groups and six predicted fungal functional groups showed significant $(p<0.05)$ 
relationships with elevation (Fig. S11, Fig. S12). The relative abundance of 15 bacterial functional groups and four fungal functional groups showed significant $(p<$ 0.05) correlations with MAT, and the relative abundance of 12 bacterial functional groups and five fungal functional groups were significantly $(p<0.05)$ correlated with pH (Fig. 5c).

\section{Discussion}

We found that soil bacterial and fungal communities had contrasting diversity patterns along an extensive elevational gradient on Mt. Kilimanjaro. Bacterial diversity patterns were U-shaped, while fungal diversity decreased monotonically with elevation. These results contrast with previous studies, that occurred along shorter gradients or homogenous environmental factors, exploring bacterial and fungal diversity along mountain gradients that found consistent decreasing (Nottingham et al., 2018) or no detectable (Shen et al., 2014) patterns. Our results were identical with one study on the Kohala Volcano of Hawai'i that found contrasting elevational diversity patterns with a hump-shaped trend for bacteria and an increasing trend for fungi (Peay et al., 2017). A recent global-scale study of soil microbes observed contrasting patterns across the latitudinal gradient - fungal diversity decreased with latitude, but bacterial diversity exhibit a hump-shaped pattern with latitude (Bahram et al., 2018). Thus, our results, together with the two previous studies, highlight the disparities between bacterial and fungal community diversity patterns along gradients. In fact, when we drill down and explore a finer resolution of 
taxonomic diversity (phyla and classes) within bacterial and fungal communities, the patterns of diversity become more complex. For example, much like the entire bacterial community, the diversity of Acidobacteria, Actinobacteria, Alphaproteobacteria and Gammaproteobacteria followed a U-shaped elevational pattern, whereas Gemmatimonadetes, Verrucomicrobia, Betaproteobacteria and Deltaproteobacteria diversity increased with elevation. Likewise, the diversity of Archaeorhizomycetes, Pezizomycetes, Saccharomycetes and Tremellomycetes followed the fungal community trend of decreasing with elevation, however, the diversity of Dothideomycetes, Leotiomycetes, Sordariomycetes and Agaricomycetes exhibited a hump-shaped pattern. Undoubtedly, the diversity patterns of dominant (with higher relative abundance) phyla and classes contributed significantly to the overall community pattern - highlighting that generalizing the response of bacterial and fungal community diversity patterns as a whole may hide important responses within less common, but still functionally important taxa (Yeh et al., 2019). Nonetheless, these observed microbial diversity patterns indicate niche differentiation (environmental conditions differentiation) among taxa along gradients (Prosser et al., 2007; Fierer et al., 2007).

Our data indicate that, in general, bacterial and fungal community diversity patterns are influenced by different ecological drivers and the role of local and regional drivers may also differ between these two diverse groups. We found that local factors, such as soil $\mathrm{pH}$, predicted bacterial elevational diversity patterns, not only for the whole community, and many of the phyla as well. Our field sites had a 
wide range of soil $\mathrm{pH}$, from 3.82-7.80, resulting in a strong correlation between bacterial diversity and soil $\mathrm{pH}$ - a pattern observed in other elevational studies (Shen et al., 2013; Wang et al., 2015; Shen et al., 2019). Additionally, along our gradients of sites, soil pH was highly correlated with the diversity of four dominant bacterial phyla including Alphaproteobacteria, Acidobacteria, Actinobacteria and Gammaproteobacteria (Table S5). Identically, pH strongly predicted bacterial diversity across latitudinal gradient (Fierer and Jackson, 2006; Chu et al., 2010; Karimi et al., 2018). Despite the importance of $\mathrm{pH}$, it should be noted that other factors like MAP, TC, TN, NDVI and C/N, that were significantly correlated with $\mathrm{pH}$, contributed to the variation of bacterial diversity (Fig. S1, Fig. 1c). The results of random forest analysis revealed that MAP (11.35\% importance) were the second important factor for predicting bacterial diversity. We infer that precipitation might indirectly affect bacterial diversity by mediating other environmental factors such as pH and NDVI (Angel et al., 2010; Tian et al., 2018).

While local-scale variation in soil properties, $\mathrm{pH}$, predicted bacterial diversity, larger-scale patterns in climate, temperature (MAT), predicted fungal diversity. This result was supported by both spearman correlation analysis (Table S1) and mixed-effect models, the latter of which found that MAT was a unique key factor compared with other explanatory variables (Table 2). MAT was significantly correlated with the diversity of specific fungal phyla and classes, such as Ascomycota, Archaeorhizomycetes, Pezizomycetes, Leotiomycetes, Saccharomycetes and Tremellomycetes; yet, not all phyla/class diversity were best predicted by MAT. Some 
phyla and class diversity, such as Glomeromycota, Chytridiomycota, Dothideomycetes, Sordariomycetes and Agaricomycetes were correlated with soil pH (Table S2). Our results showed that $\mathrm{pH}$ (7.98\% importance) was the second contributor for predicting fungal diversity (Fig. 1d). These results are consistent with a recent global study by Bahram et al. (2018) that found that MAT was the best predictor for the richness of the entire fungal community as well as the major ascomycete classes; however, the richness of Glomeromycota and Chytridiomycota was better predicted by soil $\mathrm{pH}$. Fungal species typically have a wider $\mathrm{pH}$ optimal growth than bacterial taxa, as revealed by pure culture and gene sequencing studies (Nevarez et al., 2009; Rousk et al., 2010) - thus, it is not surprising that their diversity patterns are less responsive than bacteria to local-scale shifts in $\mathrm{pH}$. Collectively, our study emphasizes the pivotal role of temperature in driving fungal elevational diversity patterns.

Fungi play important ecological roles as decomposers, mutualists and pathogens of plants, thus we hypothesized that a significant plant productivity-fungal diversity relationship would exist along the elevational gradients we measured. This hypothesis emerged from two complimentary theories developed to understand diversity patterns across landscapes: 1) the species-energy theory that predicts that species richness increases with increasing available energy, such as resource production (Wright, 1983), and 2) the productivity-diversity hypothesis that predicts that the availability of growth-limiting resources in a location limits the diversity of biotic communities at that location (Tilman, 1982; Waldrop et al., 2006). A meta-analysis found that plant productivity contributes to species richness patterns across taxa at the regional scale 
(Gillman and Wright, 2006). Yet, we unexpectedly found no significant relationship between plant productivity (NDVI) and the diversity of the entire fungal community using both spearman correlation analysis and mixed-effect models (Table 2, Table S1). While surprising, previous studies on fungi conducted at the regional or global scale found that fungal diversity was not related to plant productivity across latitudes (Tedersoo et al., 2014; Yang et al., 2017). Plant productivity is mainly driven by precipitation at Mt. Kilimanjaro, as revealed by previous studies (Ensslin et al., 2015; Peters et al., 2016). Our spearman correlation analyses showed that NDVI was highly ( $\rho=0.9, P<0.5)$ correlated with MAP, but not significant $(P>0.5)$ with MAT (Fig. S1). In this study, the influence of other factors, such as temperature (this study and Tedersoo et al., 2014) and plant diversity (Yang et al., 2017) appear to be larger drivers than plant productivity in predicting fungal diversity patterns at the community scale. However, when we look at specific community member guilds, plant productivity significantly and positively correlated with the diversity of Glomeromycota, Dothideomycetes and Sordariomycetes (Table S1). Not surprisingly, the functional guilds that closely interact with plants - arbuscular mycorrhizal fungi, endophyte fungi and saprotropic fungi - have a positive fungal diversity-plant productivity relationship (Table S3; Hiiesalu et al., 2017; Yang et al., 2017). Thus, in partial support of our hypothesis, significant productivity-diversity relationships occur for guilds that closely interact with plants, but once again, drivers of patterns at the larger-community scale and the more fine phyla/class/guild scale differ. Together, these findings underline the close interaction of host plant growth with specific fungal 
groups, especially arbuscular mycorrhizal fungi, and that the drivers of diversity patterns can shift at different taxonomic scales.

The plant diversity hypothesis states that greater plant diversity increases the range of organic substrates entering soil thus creating niche space for heterotrophic fungi (Lodge, 1997; Hooper et al., 2000), and is an alternative hypothesis for what drives soil fungal diversity along gradients. Although plant diversity was not directly assessed in this study, previous studies on the same plots found that plant species richness significantly decreased with increasing elevation on the southern slope of Mt. Kilimanjaro, and the patterns were largely predicted by MAT (Hemp, 2006; Peters et al., 2016). Thus, our data together with data shown by Peters et al. (2016), indicated a potential coupling of plant and fungal diversity, as we found significant relationships between fungal diversity and MAT. These results also suggest that plant diversity impacts fungal diversity to a greater degree than bacterial diversity, a finding that is consistent with recent results that showed plant richness significantly correlated with soil fungal diversity, but not with bacterial diversity, from a plant richness manipulation experiment (Dassen et al., 2017; Chen et al., 2019). Actually, the significant plant diversity-fungal diversity relationships have been observed in natural regional-scale grassland ecosystems (Yang et al., 2017; Chen et al., 2017).

Our data suggest that the combination of temperature and soil $\mathrm{pH}$ are the strongest predictor of microbial community composition. Similar to our diversity patterns, - $\mathrm{pH}$ and temperature - were the best predictors for bacterial and fungal composition, respectively (partial mantel test in Table S4, DistLM model in Table 3). 
Specifically, $\mathrm{pH}$ was the best predictor of the relative abundance of 12 bacterial phyla and MAT was the best predictor for the relative abundance of 14 fungal classes (Fig. 5a, Fig. 5b). Variation partitioning analyses found the combined effects of climate and local factors accounted for the largest variance of both bacterial and fungal community composition, whereas the direct effects of climate, energy and local factors contributed less to the variation (Fig. 4c, Fig. 4d). The combined effects were also important when we explored correlations between specific phyla/classes and environmental factors (Fig. 5a, Fig. 5b). For example, MAT was most correlated with the relative abundance of bacterial phyla including Alphaproteobacteria, Firmicutes, Cyanobacteria, Fibrobacteres, Armatimonadetes, Chlorobi, and $\mathrm{pH}$ was most correlated with the relative abundance of fungal classes including Dothideomycetes, Eurotiomycetes, Sordariomycetes, Monoblepharidomycetes, Glomeromycetes. Temperature could alter the composition of microbial communities through a direct effect on individuals' metabolic rates and growth (Brown et al., 2004; Zhou et al., 2016). Meanwhile, temperature may indirectly affect microbial community composition via plant attributes or soil properties (Delgado-Baquerizo et al., 2016; Delgado-Baquerizo et al., 2018; Liu et al., 2020). The reason that why pH predicted best for the community composition derives from two (but not limited) general explanations (Lauber et al., 2008; Rousk et al., 2010). First, pH directly imposes a physiological stress for individual's growth (Bárcenas-Moreno et al., 2016; Rath et al., 2019). Second, $\mathrm{pH}$ is not a direct influencing factor, but instead as an integrated functional index, because lots of soil characteristics (e.g., salinity, nutrients 
availability and organic matter) are often directly or indirectly related to soil $\mathrm{pH}$ (Siciliano et al., 2014; Zeng et al., 2016; Rath et al., 2019). In addition to $\mathrm{pH}$ and MAT, other local and climate factors played significant roles in shaping bacterial and fungal community compositions. For example, MAP and TN were significantly correlated with some bacterial phyla (e.g. Acidobacteria, Chloroflexi) and fungal classes (e.g. Dothideomycetes, Wallemiomycetes). Indeed, the roles of precipitation, temperature, $\mathrm{pH}$ and nutrients influencing soil bacterial and fungal community composition has been reported in agricultural (Lauber et al., 2008, Sun et al., 2016), forest (Angel et al., 2010; Tian et al., 2018), tundra (Shen et al., 2015; Shi et al., 2015), grassland (Chen et al., 2016; Chen et al., 2017) and desert ecosystems (Fierer et al., 2012; Chu et al., 2016). Even at the global scale, the integrated effects of climate and local factors influenced the composition of soil bacterial and fungal communities (Tedersoo et al., 2014; Leff et al., 2015; Prober et al., 2015; Bahram et al., 2018). These results suggest that, to a large extent, climate and local factors jointly determined bacterial and fungal community compositions.

\section{Conclusion}

In summary, we found a U-shaped diversity pattern for soil bacteria and a monotonically decreasing diversity pattern for soil fungi across elevational gradients on Mt. Kilimanjaro. The contrasting patterns resulted largely from two different processes, local and climate processes for bacteria and fungi, respectively. These results highlight the disparity of elevational diversity patterns between bacteria and 
fungi, which were attributed to different environmental drivers. Further, our results suggest that generalize the response of bacterial and fungal community diversity patterns as a whole may hide important responses within less common, but still functionally important taxa. We found significant productivity-diversity relationships between plant productivity and some fungal specific taxonomic or functional groups. Finally, we found that climate and local factors together influenced bacterial and fungal community composition. These findings enhanced our understanding of the formation and maintenance of microbial diversity along elevation, as well as microbial responses to climate change in montane ecosystems.

\section{Experimental procedures}

Study site

Mt. Kilimanjaro $\left(2^{\circ} 45^{\prime}-3^{\circ} 25^{\prime} \mathrm{S} ; 37^{\circ} 00^{\prime}-37^{\circ} 43^{\prime} \mathrm{E}\right)$, located $300 \mathrm{~km}$ south of the equator in Tanzania (East Africa), is the highest mountain in Africa and the highest free-standing mountain on the Earth. It rises from savanna plains at $700 \mathrm{~m}$ elevation to a snow-clad summit at an elevation of $5895 \mathrm{~m}$ a.s.l. The terrain is extremely complex with huge changes of inclinations and slopes. It is an eroded relic of an ancient volcano with three peaks (Shira, Mawenzi and Kibo) and has a diameter of 90 km from northwest to southeast. Mt. Kilimanjaro is characterized by a typical equatorial day-time climate (Hemp, 2006). The precipitation regime follows a bimodal pattern with a long rainy season from March to May and a short rainy season between October and December. The mean annual temperature (MAT), ranges from 5 
to $25{ }^{\circ} \mathrm{C}$, decreases almost linearly with elevation. The mean annual precipitation (MAP), ranges from 500 to $3000 \mathrm{~mm}$, shows a unimodal pattern with a peak at 2200 m a.s.l.

Five elevations, namely at 767, 1920, 2850, 3880 and 4190 m were selected, representing five typical vegetation types with Lowland dry broadleaf forest, lower montane forest, Podocarpus forest, Erica bush forest, and Helichrysum cushion, respectively. All selected sites were natural forest and alpine ecosystems. A detailed description of site characteristics was summarized in Table 1.

\section{Soil sampling and plant data collection}

We collected soil samples from the southern slope of Mt. Kilimanjaro in October 2014. At each elevation, four independent replicate plots $(5 \times 5 \mathrm{~m}$; about $100 \mathrm{~m}$ apart $)$ were selected. In each plot, five top-soil samples $(0-10 \mathrm{~cm}$ depth directly below the litter layer) were taken randomly and composited together into a single sample. The fresh soil samples were sieved through a $2 \mathrm{~mm}$ sieve after roots and residues were removed. Samples were separated into two portions: one was stored at $4{ }^{\circ} \mathrm{C}$ to determine the chemical properties and the other was frozen $\left(-20{ }^{\circ} \mathrm{C}\right)$ until DNA extraction.

Normalized Difference Vegetation Index (NDVI) was used as a proxy for net plant productivity. We collected NDVI data from the Moderate Resolution Imaging Spectroradiometer (MODIS) aboard NASA's Terra satellites (https://ladsweb.nascom.nasa.gov/data/search.html) that were updated once every 8 
days with 250 m resolution. Specifically, the NDVI in October 2014 was chosen at the elevation level based on the coordinate of longitude and latitude.

\section{DNA sequencing and chemical properties}

DNA was extracted using the MoBio PowerSoil DNA isolation kit (MoBio, Carlsbad, CA, USA) following the manufacturer's instructions. For bacterial community composition, 515f/806r primer sets (515f, GTGYCAGCMGCCGCGGTAA, 806r, GGACTACNVGGGTWTCTAAT) were used to amplify (triplicate reactions for each sample) the 16S rRNA gene (cited by Earth Microbiome Project). For fungal community composition, ITS1f/ITS2 primer pair (ITS1f, CTTGGTCATTTAGAGGAAGTAA, ITS2, GCTGCGTTCTTCATCGATGC) was selected to amplify the ITS1 region of the rRNA gene (cited by Earth Microbiome Project). A unique 10-base pair Golay barcode was included between the 806r/ITS2 primer and the Nextera adapter sequence. All PCR reactions were performed in $25 \mu \mathrm{L}$ reaction systems including $13 \mu \mathrm{L}$ of Phusion Master Mix (NewEngland Biolabs, USA), $0.5 \mu \mathrm{L}$ each of $10 \mu \mathrm{M}$ forward and reverse primers, 1

$\mu \mathrm{L}$ template DNA (20 ng $\mu \mathrm{L}^{-1}$ ), and $10 \mu \mathrm{L} \mathrm{H}_{2} \mathrm{O}$. Thermal cycling included an initial denaturation step at $95{ }^{\circ} \mathrm{C}$ for $1 \mathrm{~min}$, followed by 30 cycles of $95{ }^{\circ} \mathrm{C}$ for $30 \mathrm{~s}, 55^{\circ} \mathrm{C}$ for $30 \mathrm{~s}$, and $72{ }^{\circ} \mathrm{C}$ for $30 \mathrm{~s}$, with a final extension stage of $72{ }^{\circ} \mathrm{C}$ for $7 \mathrm{~min}$. $16 \mathrm{~S}$ rRNA amplicons and ITS amplicons were pooled separately and then sequenced with Illumina MiSeq instrument (Illumina, San Diego, CA, USA). Raw sequence data were processed using the QIIME v1.9 pipeline, where sequences were quality filtered 
(script: split_libraries.py; parameters: min_seq_length $=200$, max_ambig $=0$, and min_qual_score $=25$ ), chimera checked, OTU clustered and taxonomy assignment (Caporaso et al., 2012). USEARCH algorithm was utilized to conduct chimera detection and OTUs clustering (97\% similarity) (Edgar, 2010). Taxonomy was identified for each OTU using the RDP classifier (Wang et al., 2007) trained on the Greengenes (McDonald et al., 2012) and UNITE (Abarenkov et al., 2010) databases for bacterial and fungal sequences. Samples were rarefied to 30,276 and 49,326 sequences per sample for bacteria (30,276-36,913 sequences) and fungi (49,326-58,227 sequences), respectively. Functions were predicted based on bacterial and fungal taxa using the Functional Annotation of Prokaryotic Taxa (FAPROTAX) database (http://www.zoology.ubc.ca/louca/FAPROTAX/) and FUNGuild database (http://www.stbates.org/guilds/app.php). The rarified OTU/taxon tables were first translated into function tables, based on taxon-function annotations in the FAPROTAX and FUNGuild database. Then the relative abundance of each functional group was calculated based on the number of sequences per sample. The sequencing data have been deposited in the National Center for Biotechnology Information (NCBI) Sequence Read Archive (SRA) under the accession number PRJNA525365.

Soil total carbon (TC) and total nitrogen (TN) content was measured using a dry combustion elemental analyzer at $950^{\circ} \mathrm{C}$ (Vario EL II, Hanau, Germany)( Peters et al., 2016). Soil $\mathrm{pH}$ was determined in water (soil to water ratio 1:5)( $\mathrm{AB} 15 \mathrm{pH}$ meter, Accumet, Fisher Scientific). 


\section{Statistical analyses}

We calculated OTU richness, Pielou's evenness and Shannon index for the measured bacterial and fungal communities. In addition, we estimated these indices for 11 bacterial phyla and five fungal phyla and 10 fungal classes based on the same sequencing depth (Table 2). To test for the effects of elevation on diversity, the linear or quadratic model was selected based on the lower value of Akaike's information criterion (AIC). Spearman's rank correlations were used to examine the relationships between diversity and environmental variables (elevation, MAT, MAP, NDVI, pH, TC, $\mathrm{TN}$ and $\mathrm{C} / \mathrm{N}$ ). The effects of elevation and environmental factors on diversity were tested by linear mixed-effects models using the R package ImerTest, with elevation fitted as a random effect in every model, and using maximum likelihood to assess the significance of the fixed effects. We started with full models with all seven variables as fixed effects, and reduced these to final models containing only significant variables. To test the relative importance of environmental variables in driving bacterial and fungal diversity, we used random forest analysis using the R package randomForest. We performed the regression using the 'randomForest' function. The importance of variables was determined by the value of \%IncMSE (increased in mean squared error) calculated by the 'importance' function. Basically, we classified the measured environmental variables to three categories: climate factors (MAT and MAP), energy factors (NDVI and TC), local factors ( $\mathrm{pH}, \mathrm{TN}$ and $\mathrm{C} / \mathrm{N}$ ).

Community compositional dissimilarities were estimated based on the Bray-Curtis distance of OTU abundance table. To examine the elevational differences 
in compositional dissimilarities, principal co-ordinates analysis (PCoA) and permutational multivariate analysis of variance (PERMANOVA) were performed in $\mathrm{R}$ package vegan. An exponential model was selected to test the relationship between dissimilarity of bacterial and fungal communities with elevation difference. Compositional dissimilarities among sites (beta diversity) was partitioned into replacement and richness difference components (Podani family, Sørensen dissimilarities) using the R package adespatial. Partial Mantel tests were used to test the correlations between environmental variables and community composition. The percentages of explained variations in community composition by variables were tested through distance-based multivariate analysis for a linear model (DistLM) which were conducted in DISTLM_forward3 software (Anderson, 2003). Variation partitioning analyses (VPA) in R package vegan were performed to show the independent or joint effects of three grouping environmental factors (climate, local and energy) on explaining the variations in community composition. Additionally, we also performed VPA based on regional (MAT, MAP and NDVI) and local (pH, TC, TN and C/N) factors partition criterion. Random forest analysis was used to estimate the predictability of environmental variables on the relative abundance of specific phyla or classes.

For the predicted functional groups, a linear or quadratic model was selected to test the relationship between the diversity and the relative abundance of functional groups and elevation. Spearman's rank correlations were used to examine the relationships between the relative abundance of functional groups and environmental 
variables. Random forest analysis was used to estimate the predictability of environmental variables on the relative abundance of functional groups.

\section{Acknowledgements}

We thank Zhongwang Jing and Xin Wang for assistance with data analyses. This work was supported by the National Natural Science Foundation of China (41671254, 41701273, 41671253), the Second Tibetan Plateau Scientific Expedition and Research Program (2019QZKK0306, 2019QZKK0308), and the State Key Laboratory of Urban and Regional Ecology (SKLURE2017-1-7). The publication was supported by the Russian Government Program of Competitive Growth of Kazan Federal University and with the support of the "RUDN University program 5-100". Our work was supported by the Tanzanian Commission for Science and Technology (COSTECH), the Tanzania Wildlife Research Institute (TAWIRI), and the Mount Kilimanjaro National Park (KINAPA). Funds for this research were provided by the German Research Foundation - Research Unit 1246 - KiLi within the project KU 1184/20-3.

\section{Conflict of Interest}

The authors declare no conflict of interest. 


\section{References}

Abarenkov, K., Henrik Nilsson, R., Larsson, K.H., Alexander, I.J., Eberhardt, U., Erland, S., et al. (2010) The UNITE database for molecular identification of fungi - recent updates and future perspectives. New Phytol 186: 281-285.

Anderson, M.J. (2003) DISTLM forward: a FORTRAN computer program to calculate a distance-based multivariate analysis for a linear model using forward selection. University of Auckland, Auckland, New Zealand.

Angel, R., Soares, M.I., Ungar, E.D., and Gillor, O. (2010) Biogeography of soil archaea and bacteria along a steep precipitation gradient. ISME J 4: 553-563.

Bahram, M., Hildebrand, F., Forslund, S.K., Anderson, J.L., Soudzilovskaia, N.A., Bodegom, P.M., et al. (2018) Structure and function of the global topsoil microbiome. Nature 560: 233-237.

Bárcenas-Moreno, G., Bååth, E., and Rousk, J. (2016) Functional implications of the $\mathrm{pH}$-trait distribution of the microbial community in a re-inoculation experiment across a pH gradient. Soil Biol Biochem 93: 69-78.

Brown, J.H., Gillooly, J.F., Allen, A.P., Savage, V.M., and West, G.B. (2004) Toward a metabolic theory of ecology. Ecology 85: 1771-1789.

Bryant, J.A., Lamanna, C., Morlon, H., Kerkhoff, A.J., Enquist, B.J., and Green, J.L. (2008) Microbes on mountainsides: Contrasting elevational patterns of bacterial and plant diversity. Proc Natl Acad Sci USA 105: 11505-11511.

Caporaso, J.G., Lauber, C.L., Walters, W.A., Berg-Lyons, D., Huntley, J., Fierer, N., et al. (2012) Ultra-high-throughput microbial community analysis on the Illumina 
HiSeq and MiSeq platforms. ISME J 6: 1621-1624.

Chen, L., Xiang, W.H., Wu, H.L., Ouyang, S., Zhou, B., Zeng, Y.L., et al. (2019) Tree species identity surpasses richness in affecting soil microbial richness and community composition in subtropical forests. Soil Biol Biochem 130: 113-121.

Chen, Y.L., Ding, J.Z., Peng, Y.F., Li, F., Yang, G.B., Liu, L., et al. (2016) Patterns and drivers of soil microbial communities in Tibetan alpine and global terrestrial ecosystems. J Biogeogr 43: 2027-2039.

Chen, Y.L., Xu, T.L., Veresoglou, S.D., Hu, H.W., Hao, Z.P., Hu, Y.J., et al. (2017) Plant diversity represents the prevalent determinant of soil fungal community structure across temperate grasslands in northern China. Soil Biol Biochem 110: $12-21$.

Chu, H.Y., Fierer, N., Lauber, C.L., Caporaso, J.G., Knight, R., and Grogan, P. (2010) Soil bacterial diversity in the Arctic is not fundamentally different from that found in other biomes. Environ Microbiol 12: 2998-3006.

Chu, H.Y., Sun, H.B., Tripathi, B.M., Adams, J.M., Huang, R., Zhang, Y.J., et al. (2016) Bacterial community dissimilarity between the surface and subsurface soils equals horizontal differences over several kilometers in the western Tibetan Plateau. Environ Microbiol 18: 1523-1533.

Colwell, R.K., Rahbek, C. and Gotelli, N.J. (2004) The mid-domain effect and species richness patterns: what we have learned so far? Am Nat 163: E1-E23.

Dassen, S., Cortois, R., Martens, H., de Hollander, M., Kowalchuk, G.A., van der Putten, W.H., et al. (2017) Differential responses of soil bacteria, fungi, archaea 
and protists to plant species richness and plant functional group identity. Mol Ecol 26: 4085-4098.

Delgado-Baquerizo, M., Maestre, F.T., Reich, P.B., Trivedi, P., Osanai, Y., Liu, Y.R., et al. (2016) Carbon content and climate variability drive global soil bacterial diversity patterns. Ecol Monogr 86: 373-390.

Delgado-Baquerizo, M., Fry, E.L., Eldridge, D.J., de Vries, F.T., Manning, P., Hamonts, K., et al. (2018) Plant attributes explain the distribution of soil microbial communities in two contrasting regions of the globe. New Phytol 219: $574-587$.

Ding, J.J., Zhang, Y.G., Deng, Y., Cong, J., Lu, H., Sun, X., et al. (2015) Integrated metagenomics and network analysis of soil microbial community of the forest timberline. Sci Rep 5: 7994.

Edgar, R.C. (2010) Search and clustering orders of magnitude faster than BLAST. Bioinformatics 26: 2460-2461.

Evans, K.L., Warren, P.H., and Gaston, K.J. (2005) Species-energy relationships at the macroecological scale: a review of the mechanisms. Biol Rev 80: 1-25.

Ensslin, A., Rutten, G., Pommer, U. Zimmermann, R., Hemp, A., and Fischer, M. (2015) Effects of elevation and land use on the biomass of trees, shrubs and herbs at Mount Kilimanjaro. Ecosphere 6: 1-15.

Fierer, N., and Jackson, R.B. (2006) The diversity and biogeography of soil bacterial communities. Proc Natl Acad Sci USA 103: 626-631.

Fierer, N., Bradford, M.A., and Jackson, R.B. (2007) Toward an ecological 
calssification of soil bacteria. Ecology 88: 1354-1364.

Fierer, N., McCain, C.M., Meir, P., Zimmermann, M., Rapp, J.M., Silman, M.R., et al. (2011) Microbes do not follow the elevational diversity patterns of plants and animals. Ecology 92: 797-804.

Fierer, N., Leff, J.W., Adams, B.J., Nielsen, U.N., Bates, S.T., Lauber, C.L., et al. (2012) Cross-biome metagenomic analyses of soil microbial communities and their functional attributes. Proc Natl Acad Sci USA 109: 21390-21395.

Furhman, J.A., Steele, J.A., Hewson, I., Schwalbach, M.S., Brown, M.V., Green, J.L., et al. (2008) A latitudinal diversity gradient in planktonic marine bacteria. Proc Natl Acad Sci USA 105: 7774-7778.

Gaston, K. (2000) Global patterns in biodiversity. Nature 405: 220-227.

Geml, J., Pastor, N., Fernandez, L., Pacheco, S., Semenova, T.A., Becerra, A.G., et al. (2014) Large-scale fungal diversity assessment in the Andean Yungas forests reveals strong community turnover among forest types along an altitudinal gradient. Mol Ecol 23: 2452-2472.

Gillman, L.N., and Wright, S.D. (2006) The influence of productivity on the species richness of plants: a critical assessment. Ecology 87: 1234-1243.

Hawkins, B.A, Field, R., Cornell, H.V., Currie, D.J., Guégan, J., Kaufman, D.M., et al. (2003) Energy, water and broad-scale geographic patterns of species richness. Ecology 84: 3105-3117.

Hemp, A. (2006) Continuum or zonation? Altitudinal gradients in the forest vegetation of Mt. Kilimanjaro. Plant Ecol 184: 27-42. 
Hendershot, J.N, Read, Q.D., Henning, J.A., Sanders, N.Z., and Classen, A.T. (2017) Consistently inconsistent drivers of microbial diversity and abundance at macroecological scales. Ecology 98: 1757-1763.

Hiiesalu, I., Bahram, M., and Tedersoo, L. (2017) Plant species richness and productivity determine the diversity of soil fungal guilds in temperate coniferous forest and bog habitats. Mol Ecol 26: 4846-4858.

Hooper, D.U., Bignell, D.E., Brown, V.K., Brussaard, L., Dangerfield, J.M., Wall, D.H., et al. (2000) Interactions between Aboveground and Belowground Biodiversity in Terrestrial Ecosystems: Patterns, Mechanisms, and Feedbacks. Bioscience 50: 1049-1061.

Karimi, B., Terrat, S., Dequiedt, S., Saby, N.P.A., Horrigue, W., Lelièvre, M., et al. (2018) Biogeography of soil bacteria and archaea across France. Sci Adv 4: eaat1808.

Lauber, C.L., Strickland, M.S., Bradford, M.A., and Fierer, N. (2008) The influence of soil properties on the structure of bacterial and fungal communities across land-use types. Soil Biol Biochem 40: 2407-2415.

Leff, J.W., Jones, S.E., Prober, S.M., Barberán, A., Borer, E.T., Firn, J.L., et al. (2015) Consistent responses of soil microbial communities to elevated nutrient inputs in grasslands across the globe. Proc Natl Acad Sci USA 112: 10967-10972.

Li, G.X., Xu, G.R., Shen, C.C., Tang, Y., Zhang, Y.X., and Ma, K.M. (2016) Contrasting elevational diversity patterns for soil bacteria between two ecosystems divided by the treeline. Sci China Life Sci 59: 1177-1186. 
Liu, S.E., Wang, H., Tian, P., Yao, X., Sun, H., Wang, Q.K., et al. (2020) Decoupled diversity patterns in bacteria and fungi across continental forest ecosystems. Soil Biol Biochem 144: 107763.

Lodge, D.J. (1997) Factors related to diversity of decomposer fungi in tropical forests. Biodivers Conserv 6: 681-688.

Lomolino, M.V. (2001) Elevation gradients of species-density: historical and prospective views. Glob Ecol Biogeogr 10: 3-13.

Martiny, J.B.H., Bohannan, B.J., Brown, J.H., Colwell, R.K., Fuhrman, J.A., Green, J.L., et al. (2006) Microbial biogeography: putting microorganisms on the map. Nat Rev Microbiol 4: 102-112.

McCain, C.M. (2004) The mid-domain effect applied to elevational gradients: species richness of small mammals in Costa Rica. J Biogeogr 31: 19-31.

McCain, C.M. (2009) Vertebrate range sizes indicate that mountains may be 'higher' in the tropics. Ecol Lett 12: 550-560.

McDonald, D., Price, M.N., Goodrich, J., Nawrocki, E.P., DeSantis, T.Z., Probst, A., et al. (2012) An improved Greengenes taxonomy with explicit ranks for ecological and evolutionary analyses of bacteria and archaea. ISME J 6: 610-618.

Miyamoto, Y., Nakano, T., Hattori, M., and Nara, K. (2014) The mid-domain effect in ectomycorrhizal fungi: range overlap along an elevation gradient on Mount Fuji, Japan. ISME J 8: 1739.

Nevarez, L., Vasseur,V., Le Madec, A., Le Bras, M.A., Coroller, L., Leguérinel, I., et 
al. (2009) Physiological traits of Penicillium glabrum strain LCP 08.5568, a filamentous fungus isolated from bottled aromatised mineral water. Int J Food Microbiol 130: 166-171.

Nottingham, A.T., Fierer, N., Turner, B.L., Whitaker, J., Ostle, N.J., McNamara, N.P., et al. (2018) Microbes follow Humboldt: temperature drives plant and soil microbial diversity patterns from the Amazon to the Andes. Ecology 99: 2455-2466.

Peay, K.G., von Sperber, C., Cardarelli, E., Toju, H., Francis, C.A., Chadwick, O.A., et al. (2017) Convergence and contrast in the community structure of Bacteria, Fungi and Archaea along a tropical elevation-climate gradient. FEMS Microbiol Ecol 93: fix045.

Peters, M.K., Hemp, A., Appelhans, T., Behler, C., Classen, A., Detsch, F., et al. (2016) Predictors of elevational biodiversity gradients change from single taxa to the multi-taxa community level. Nat Commun 7: 13736.

Phillps, L.B., Hansen, A.J., Flather, C.H., and Robison-Cox, J. (2010) Applying species-energy theory to conservation: a case study for North American birds. Ecol Appl 20: 2007-2023.

Prober, S.M., Leff, J.W., Bates, S.T., Borer, E.T., Firn, J., Harpole, W.S., et al. (2015) Plant diversity predicts beta but not alpha diversity of soil microbes across grasslands worldwide. Ecol Lett 18: 85-95.

Prosser, J.I., Bohannan, B.J.M., Curtis, T.P., Ellis, R.J., Firestone, M.K., Freckleton, R.P., et al. (2007) The role of ecological theory in microbial ecology. Nat Rev 
Microbiol 5: 384-392.

Rahbek, C. (1995) The elevational gradient of species richness: a uniform pattern? Ecography 18: 200-205.

Rahbek, C. (2005) The role of spatial scale and the perception of large-scale species-richness patterns. Ecol Lett 8: 224-239.

Rath, K.M., Fierer, N., Murphy, D.V., and Rousk, J. (2019) Linking bacterial community composition to soil salinity along environmental gradients. ISME J 13: 836-846.

Rousk, J., Bååth, E., Brookes, P.C., Lauber, C.L., Lozupone, C., Caporaso, J.G.R., et al. (2010) Soil bacterial and fungal communities across a pH gradient in an arable soil. ISME J 4: 1340-1351.

Schmit, J. P. (2005) Species richness of tropical wood-inhabiting macrofungi provides support for species-energy theory. Mycologia 97: 751-761.

Shen, C.C., Xiong, J.B., Zhang, H.Y., Feng, Y.Z., Lin, X.G., Li, X.Y., et al. (2013) Soil pH drives the spatial distribution of bacterial communities along elevation on Changbai Mountain. Soil Biol Biochem 57: 204-211.

Shen, C.C., Liang, W.J., Shi,Y., Lin, X.G., Zhang, H.Y., Wu, X., et al. (2014) Contrasting elevational diversity patterns between eukaryotic soil microbes and plants. Ecology 95: 3190-3202.

Shen, C.C., Ni, Y.Y., Liang, W.J., Wang, J.J., and Chu, H.Y. (2015) Distinct soil bacterial communities along a small-scale elevational gradient in alpine tundra. Front Microbiol 6: 582. 
Shen, C.C., Shi, Y., Fan, K.K., He, J.S., Adams, J.M., Ge, Y., et al. (2019) Soil pH dominates elevational diversity pattern for bacteria in high elevation alkaline soils on the Tibetan Plateau. FEMS Microbiol Ecol 95: fiz003.

Shi, Y., Xiang, X.J., Shen, C.C., Chu, H.Y., Neufeld, J.D., Walker, V. K., et al. (2015) vegetation-associated impacts on arctic tundra bacterial and microeukaryotic communities. Appl Environ Microbiol 81: 492-501.

Siciliano, S.D., Palmer, A.S., Winsley, T., Lamb, E., Bissett, A., Brown, M.V., et al. (2014) Soil fertility is associated with fungal and bacterial richness, whereas $\mathrm{pH}$ is associated with community composition in polar soil microbial communities. Soil Biol Biochem 78: 10-20.

Singh, D., Takahashi, K., Kim, M., Chun, J., and Adams, J. M. (2012) A Hump-Backed Trend in Bacterial Diversity with Elevation on Mount Fuji, Japan. Microb Ecol 63: 429-437.

Singh, D., Lee-Cruz, L., Kim, W-S., Kerfahi, D., Chun, J., and Adams, J.M. (2014) Strong elevational trends in soil bacterial community composition on Mt. Halla, South Korea. Soil Biol Biochem 68: 140-149.

Sun, R.B., Dsouza, M., Gilbert, J. A., Guo, X.S., Wang, D.Z., Guo, Z.B., et al. (2016) Fungal community composition in soils subjected to long-term chemical fertilization is most influenced by the type of organic matter. Environ Microbiol 18: $5137-5150$.

Tedersoo, L., Bahram, M., Põlme, S., Kõljalg, U., Yorou, N.S., Wijesundera, R., et al. (2014) Global diversity and geography of soil fungal. Science 346: 1256688. 
Tian, J., He, N.P., Hale, L., Niu, S.L., Yu, G.R., Liu, Y., et al. (2018) Soil organic matter availability and climate drive latitudinal patterns in bacterial diversity from tropical to cold temperate forests. Funct Ecol 32: 61-70.

Tilman, D. (1982) Resource Competition and Community Structure. Princeton University Press, Princeton, NJ.

Waldrop, M.P., Zak, D.R., Blackwood, C.B., Curtis, C.D., and Tilman, D. (2006) Resource availability controls fungal diversity across a plant diversity gradient. Ecol Lett 9: 1127-1135.

Wang, J.T., Cao, P., Hu, H.W., Li, J., Han, L.L., Zhang, L.M., et al. (2015) Altitudinal Distribution Patterns of Soil Bacterial and Archaeal Communities Along Mt. Shegyla on the Tibetan Plateau. Microb Ecol 69: 135-145.

Wang, Q., Garrity, G.M., Tiedje, J.M., and Cole, J.R. (2007) Naive Bayesian classifier for rapid assignment of rRNA sequences into the new bacterial taxonomy. Appl Environ Microbiol 73: 5261-5267.

Wright, D. H. (1983) Species-energy theory: an extension of species-area theory. Oikos 41: 496-506.

Yang, T., Weisenhorn, P., Gilbert, J.A., Ni, Y.Y., Sun, R.B., Shi, Y., et al. (2016) Carbon constrains fungal endophyte assemblages along the timberline. Environ Microbiol 18: 2455-2469.

Yang, T., Adams, J.M., Shi, Y., He, J.S., Jing, X., Chen, L.T., et al. (2017) Soil fungal diversity in natural grasslands of the Tibetan Plateau: associations with plant diversity and productivity. New Phytol 215: 756-765. 
Yeh, C., Soininen, J., Teittinen, A., and Wang, J. (2019) Elevational patterns and hierarchical determinants of biodiversity across microbial taxonomic scales. Mol Ecol 28: 86-99.

Zeng, J., Liu, X.J., Song, L., Lin, X.G., Zhang, H.Y., Shen, C.C., et al. (2016) Nitrogen fertilization directly affects soil bacterial diversity and indirectly affects bacterial community composition. Soil Biol Biochem 92: 41-49.

Zhou, J.Z., Deng, Y., Shen, L.N., Wen, C.Q., Yan, Q.Y., Ning, D.L., et al. (2016) Temperature mediates continental-scale diversity of microbes in forest soils. Nat Commun 7: 12083. 
Table 1: Summary of the main characteristics of sampling sites. MAT, mean annual temperature; MAP, mean annual precipitation; NDVI, normalized difference vegetation index; TC, total carbon; TN, total nitrogen.

\begin{tabular}{|c|c|c|c|c|c|c|c|c|c|c|}
\hline Forest type & Longitude & Latitude & $\begin{array}{c}\text { Elevation } \\
(\mathrm{m})\end{array}$ & $\begin{array}{l}\text { MAT } \\
\left({ }^{\circ} \mathrm{C}\right) \\
\end{array}$ & $\begin{array}{l}\text { MAP } \\
(\mathrm{mm})\end{array}$ & NDVI & $\begin{array}{c}\text { TC } \\
(\mathrm{g} / \mathrm{kg})\end{array}$ & $\begin{array}{c}\mathrm{TN} \\
(\mathrm{g} / \mathrm{kg}) \\
\end{array}$ & $\mathrm{C} / \mathrm{N}$ & $\mathrm{pH}$ ranges \\
\hline Lowland dry broadleaf forest & $37^{\circ} 10^{\prime} \mathrm{E}$ & $3^{\circ} 22^{\prime} \mathrm{S}$ & 767 & 23.7 & 844.75 & 0.26 & $95.24 \pm 11.38$ & $7.42 \pm 0.71$ & $12.77 \pm 0.45$ & $7.24-7.80$ \\
\hline Lower montane forest & $37^{\circ} 14^{\prime} \mathrm{E}$ & $3^{\circ} 10^{\prime} \mathrm{S}$ & 1920 & 15.3 & 2377.52 & 0.87 & $212.24 \pm 11.31$ & $14.07 \pm 0.73$ & $15.08 \pm 0.09$ & $3.99-4.25$ \\
\hline Podocarpus forest & $37^{\circ} 15^{\prime} \mathrm{E}$ & $3^{\circ} 6^{\prime} \mathrm{S}$ & 2850 & 9.4 & 1773.00 & 0.64 & $325.85 \pm 25.16$ & $17.71 \pm 0.75$ & $18.37 \pm 0.97$ & $3.82-3.95$ \\
\hline Erica bush forest & $37^{\circ} 17^{\prime} \mathrm{E}$ & $3^{\circ} 4^{\prime} \mathrm{S}$ & 3880 & 4.5 & 1188.00 & 0.45 & $187.22 \pm 25.20$ & $9.88 \pm 1.05$ & $18.77 \pm 0.77$ & $4.73-5.17$ \\
\hline Helichrysum cushion & $37^{\circ} 19^{\prime} \mathrm{E}$ & $3^{\circ} 5^{\prime} \mathrm{S}$ & 4190 & 4.5 & 961.52 & 0.21 & $47.75 \pm 6.72$ & $3.13 \pm 0.40$ & $15.18 \pm 0.22$ & $4.45-5.65$ \\
\hline
\end{tabular}


Table 2: The effects of environmental factors on diversity were tested using linear mixed-effects models for bacteria and fungi (with elevation as a random effect). A quadratic term of elevation was included to test for non-linear effects of elevation. Marginal $\mathrm{R}^{2}$ gives the proportion of variance accounted for by the fixed effects; Conditional $\mathrm{R}^{2}$ that accounted for by both fixed and random effects. SE, standard error; MAT, mean annual temperature.

\begin{tabular}{|c|c|c|c|c|}
\hline \multicolumn{5}{|l|}{ (1) Bacteria } \\
\hline & Estimate & SE & t-value & $P$-value \\
\hline Intercept & 0.6979 & 0.3044 & 2.293 & 0.034 \\
\hline $\mathrm{pH}$ & 0.9564 & 0.3037 & 3.149 & 0.005 \\
\hline $\mathrm{pH}^{2}$ & -0.7347 & 0.2536 & -2.897 & 0.01 \\
\hline \multicolumn{5}{|c|}{ Random effects variance } \\
\hline Elevation & 0.0264 & & & \\
\hline Residual & 0.6928 & & & \\
\hline Marginal $\mathrm{R}^{2}$ & 0.327 & Conditional $\mathrm{R}^{2}$ & 0.354 & \\
\hline \multicolumn{5}{|l|}{ (2) Fungi } \\
\hline & Estimate & SE & t-value & $P$-value \\
\hline Intercept & 0 & 0.1917 & 0 & 1 \\
\hline MAT & 5.511 & 0.1967 & 2.802 & 0.011 \\
\hline \multicolumn{5}{|c|}{ Random effects variance } \\
\hline Elevation & 0.0485 & & & \\
\hline Residual & 0.7151 & & & \\
\hline Marginal $\mathrm{R}^{2}$ & 0.243 & Conditional $\mathrm{R}^{2}$ & 0.292 & \\
\hline
\end{tabular}


Table 3: Results of a distance-based linear model (DistLM) analysis determining the suite of environmental variables that describe significant and independent proportions of the variation in bacterial and fungal community composition. Variables are listed in order of importance, and they are added to the model. Values in bold indicate significant $(p<0.05)$. SS, sum of squares; MAT, mean annual temperature; MAP, mean annual precipitation; NDVI, normalized difference vegetation index; TC, total carbon; TN, total nitrogen.

\begin{tabular}{lccccc}
\hline Variable & SS(Trace) & Pseudo-F & $P$-value & Proportion & Cumulative \\
\hline (1) Bacteria & & & & & \\
pH & 16300.3135 & 13.5691 & $\mathbf{0 . 0 0 1}$ & 0.4298 & 0.4298 \\
MAT & 12380.1458 & 22.7701 & $\mathbf{0 . 0 0 1}$ & 0.3265 & 0.7563 \\
TC & 2478.1265 & 5.8612 & $\mathbf{0 . 0 0 1}$ & 0.0653 & 0.8216 \\
MAP & 1420.9976 & 3.9887 & $\mathbf{0 . 0 0 1}$ & 0.0375 & 0.8591 \\
C/N & 801.4968 & 2.4703 & $\mathbf{0 . 0 2 3}$ & 0.0211 & 0.8802 \\
TN & 494.3036 & 1.5874 & 0.097 & 0.013 & 0.8933 \\
NDVI & 195.9825 & 0.6105 & 0.838 & 0.0052 & 0.8984 \\
\hline (2) Fungi & & & & & \\
MAT & 14562.3792 & 5.7628 & $\mathbf{0 . 0 0 1}$ & 0.2425 & 0.2425 \\
MAP & 12497.197 & 6.4403 & $\mathbf{0 . 0 0 1}$ & 0.2081 & 0.4506 \\
TN & 9350.5814 & 6.3294 & $\mathbf{0 . 0 0 1}$ & 0.1557 & 0.6063 \\
TC & 3077.1171 & 2.4031 & $\mathbf{0 . 0 1 2}$ & 0.0512 & 0.6575 \\
pH & 2439.2934 & 1.7261 & 0.093 & 0.0406 & 0.6981 \\
C/N & 1474.8765 & 1.0469 & 0.373 & 0.0246 & 0.7227 \\
NDVI & 856.5974 & 0.651 & 0.831 & 0.0143 & 0.7371 \\
\hline
\end{tabular}




\section{Figures and legends}

Figure 1 a. Elevational patterns for the diversity of bacterial whole community (with green points and blue fitting curve) and specific phyla. Scaled Shannon, z-transformed Shannon index. The quadratic model was selected based on the lower value of AIC (linear, AIC = 2.79; quadratic, AIC = -20.52). b. Elevational patterns for the diversity of fungal whole community (with purple points and blue fitting curve) and specific phyla/classes. Scaled Shannon, z-transformed Shannon index. The linear model was selected based on the lower value of AIC (linear, AIC $=-7.61$; quadratic, AIC = -5.62). c. The relative importance of environmental variables for bacterial diversity (Shannon). The percentages were separated by dash line. d. The relative importance of environmental variables for fungal diversity (Shannon). The percentages were separated by dash line. MAT, mean annual temperature; MAP, mean annual precipitation; NDVI, normalized difference vegetation index; TC, total carbon; $\mathrm{TN}$, total nitrogen.

Figure 2 a. b. The relationship between dissimilarity of bacterial (a) and fungal (b) communities with elevation distance. The strength of the relationship is based on exponential models $\{y=a[1-\exp (-b x)]+c$; with parameter estimates for bacteria $(\mathrm{a}=$ $0.6381, \mathrm{~b}=0.001, \mathrm{c}=0.1872)$ and fungi $(\mathrm{a}=0.4526, \mathrm{~b}=0.0026, \mathrm{c}=0.4207)\} . \mathbf{c} . \mathbf{d}$. PCoA plots of trends in the composition of bacteria (c) and fungi (d) based on Bray-Curtis dissimilarity. For bacteria, samples were coded with different shapes and colors according to the elevations and $\mathrm{pH}$. For fungi, samples were coded with 
different shapes and colors according to the elevations and MAT. MAT, mean annual temperature.

Figure 3 Triangular plots of beta diversity comparisons (using Sørensen dissimilarity index) for bacterial and fungal communities among all sites (a, b) and among sites within elevation (c, d). Each point represents a pair of sites. Its position is determined by a triplet of values from the S (similarity), Repl (replacement) and RichDiff (richness difference) matrices; each triplet sums to 1 . Mean values of S, Repl and RichDiff are shown.

Figure 4 Results of variation partitioning analysis showing the percentages of explained variation for the composition of bacteria (a, c) and fungi (b, d). a. b. Variation was partitioned by regional factors (MAT, MAP and NDVI) and local factors $(\mathrm{pH}, \mathrm{TC}, \mathrm{TN}$ and $\mathrm{C} / \mathrm{N})$. c. d. Variation was partitioned by climate factors (MAT and MAP), energy factors (NDVI and TC) and local factors (pH, TN and C/N). MAT, mean annual temperature; MAP, mean annual precipitation; NDVI, normalized difference vegetation index; TC, total carbon; TN, total nitrogen.

Figure 5 Correlation and best random forest model for relative abundance of major bacterial phyla (a, class for Proteobacteria), relative abundance of major fungal classes (b), relative abundance of predicted functional groups (c, green dash line means predicted functional groups based on bacterial taxa, purple dash line means 
predicted functional groups based on fungal taxa). For variable selection and estimating predictability, the random forest machine-learning algorithm was used. Circle size represents the variable importance (that is, decrease in the prediction accuracy (estimated with out-of-bag cross-validation)) as a result of the permutation of a given variable. Colors represent Spearman correlations. MAT, mean annual temperature; MAP, mean annual precipitation; NDVI, normalized difference vegetation index; TC, total carbon; TN, total nitrogen. 

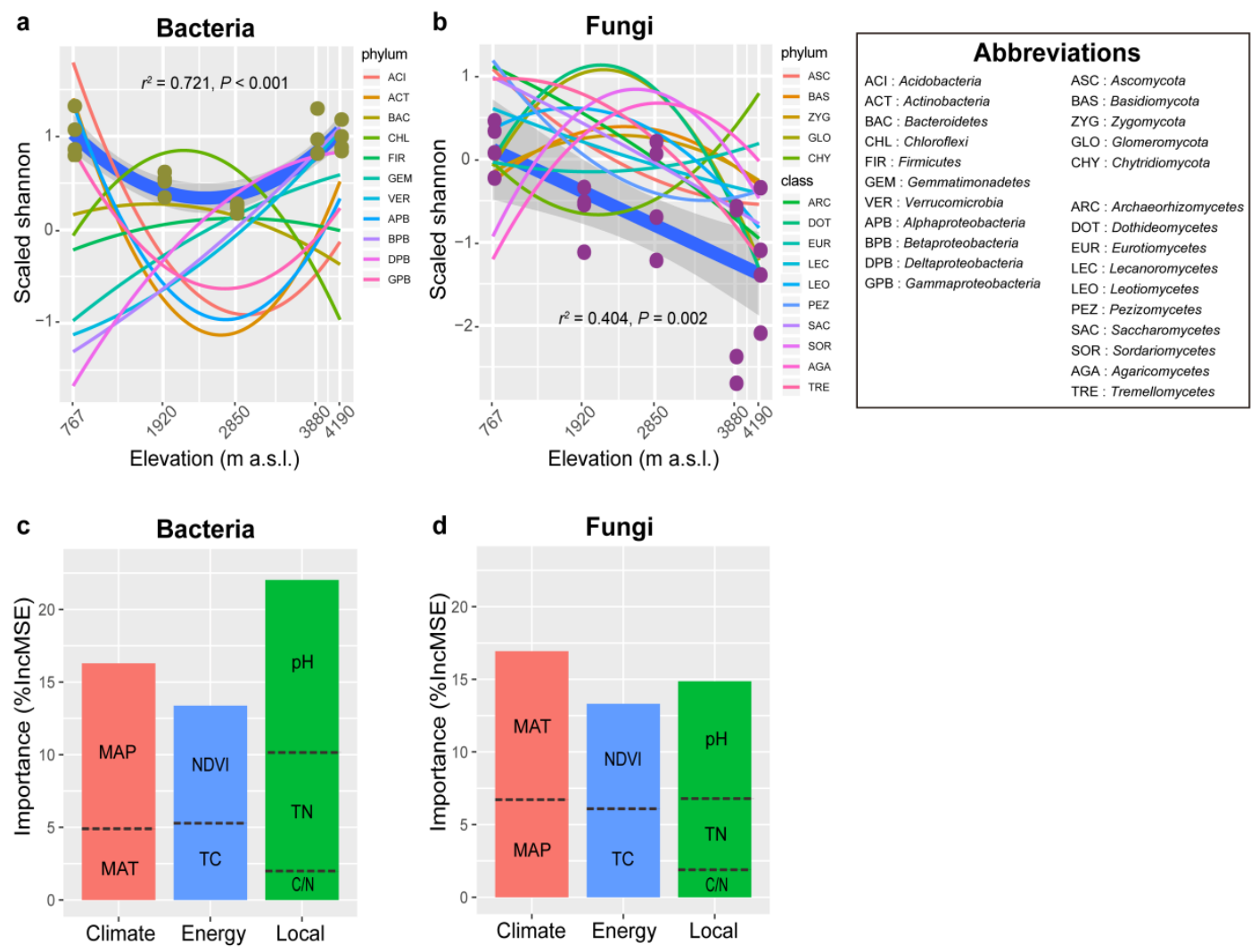

Figure 1 a. Elevational patterns for the diversity of bacterial whole community (with green points and blue fitting curve) and specific phyla. Scaled Shannon, z-transformed Shannon index. The quadratic model was selected based on the lower value of AIC (linear, AIC = 2.79; quadratic, AIC = -20.52). b. Elevational patterns for the diversity of fungal whole community (with purple points and blue fitting curve) and specific phyla/classes. Scaled Shannon, z-transformed Shannon index. The linear model was selected based on the lower value of AIC (linear, AIC $=-7.61$; quadratic, AIC = -5.62). c. The relative importance of environmental variables for bacterial diversity (Shannon). The percentages were separated by dash line. d. The relative importance of environmental variables for fungal diversity (Shannon). The 
percentages were separated by dash line. MAT, mean annual temperature; MAP, mean annual precipitation; NDVI, normalized difference vegetation index; TC, total carbon; TN, total nitrogen. 
a

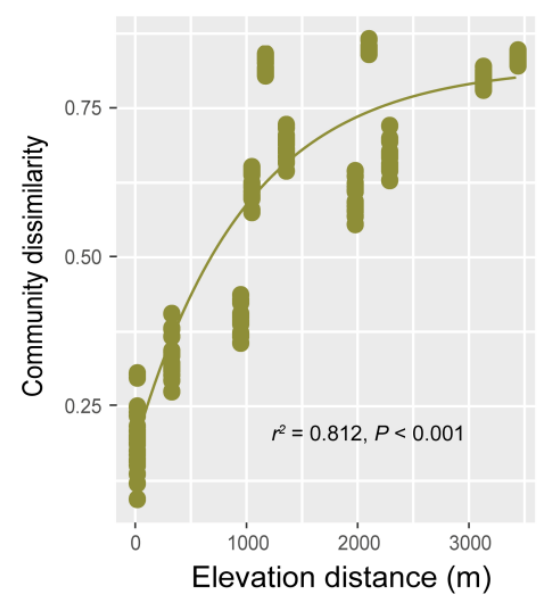

C

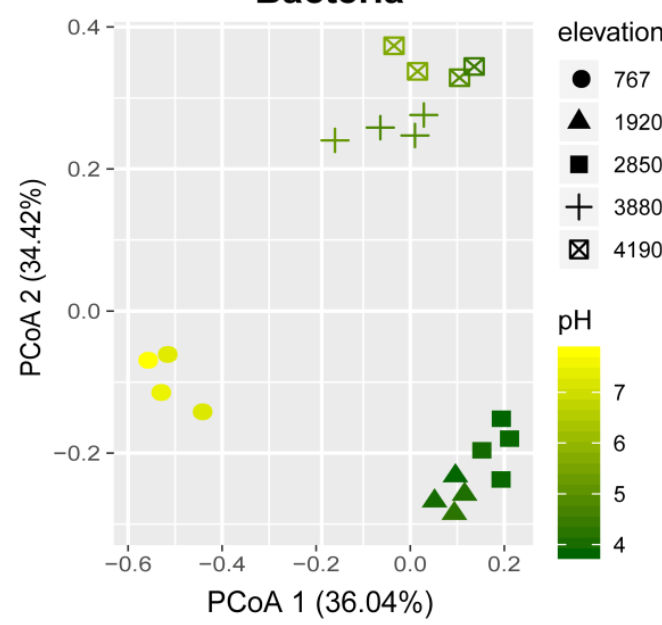

b

Fungi
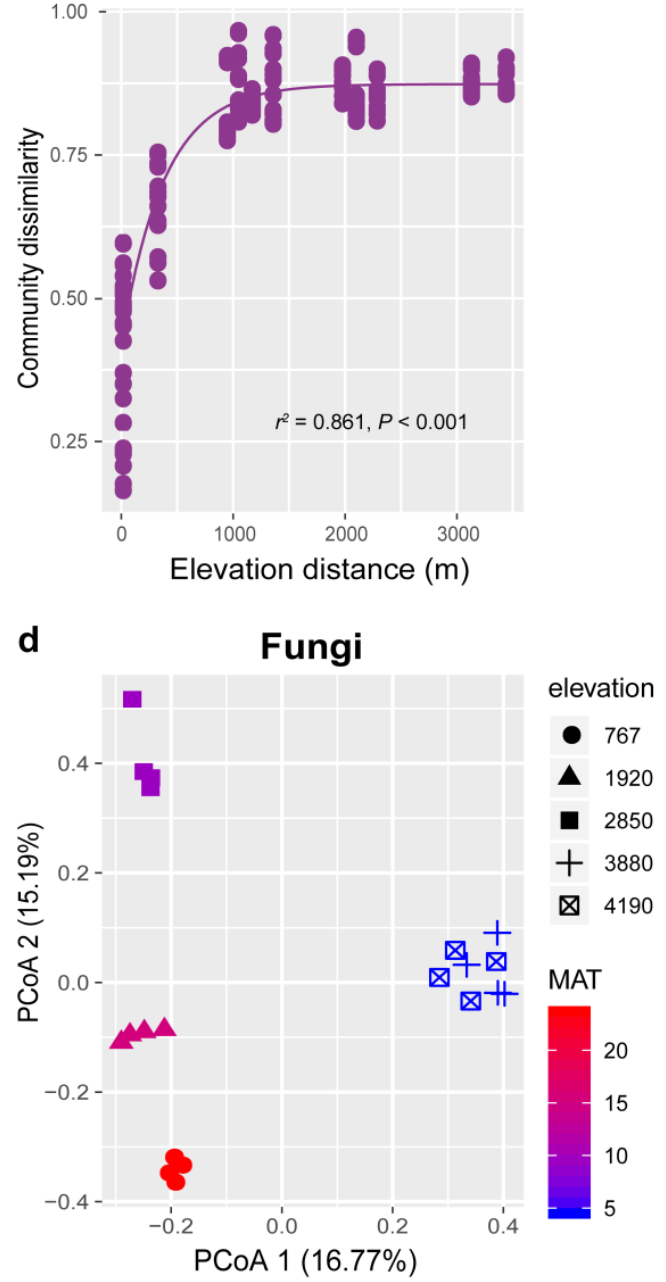

Figure 2 a. b. The relationship between dissimilarity of bacterial (a) and fungal (b) communities with elevation distance. The strength of the relationship is based on exponential models $\{y=a[1-\exp (-b x)]+c$; with parameter estimates for bacteria $(\mathrm{a}=$ $0.6381, \mathrm{~b}=0.001, \mathrm{c}=0.1872)$ and fungi $(\mathrm{a}=0.4526, \mathrm{~b}=0.0026, \mathrm{c}=0.4207)\} . \mathbf{c} . \mathbf{d}$. PCoA plots of trends in the composition of bacteria (c) and fungi (d) based on Bray-Curtis dissimilarity. For bacteria, samples were coded with different shapes and colors according to the elevations and $\mathrm{pH}$. For fungi, samples were coded with different shapes and colors according to the elevations and MAT. MAT, mean annual 
temperature.

This article is protected by copyright. All rights reserved. 
a

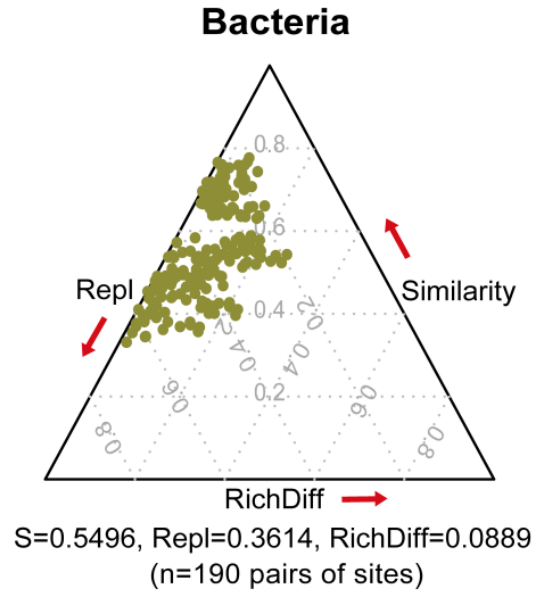

C

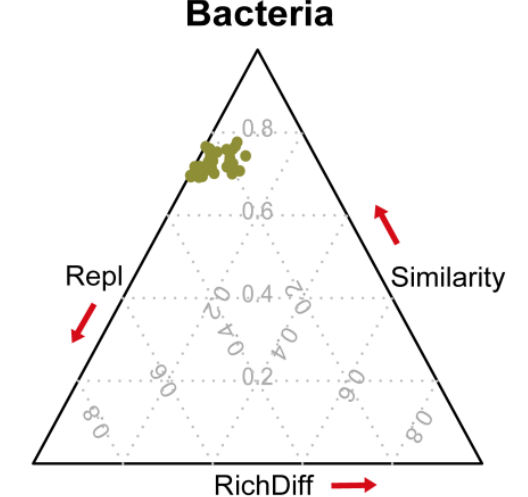

$S=0.7282$, Repl $=0.2293$, RichDiff $=0.0424$ $(n=30$ pairs of sites, within elevation) b

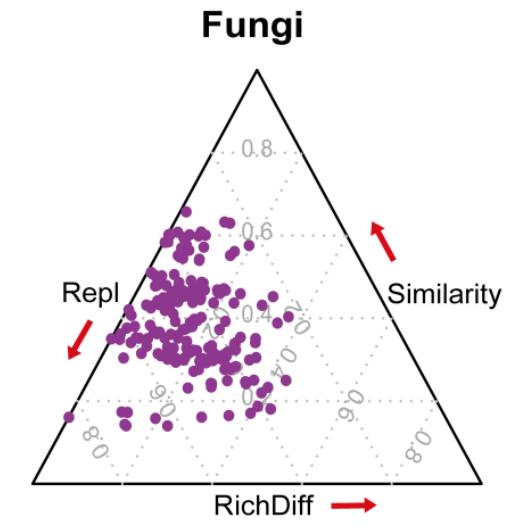

$\mathrm{S}=0.3935$, Repl=0.4499, RichDiff $=0.1566$ ( $n=190$ pairs of sites)

d

Fungi

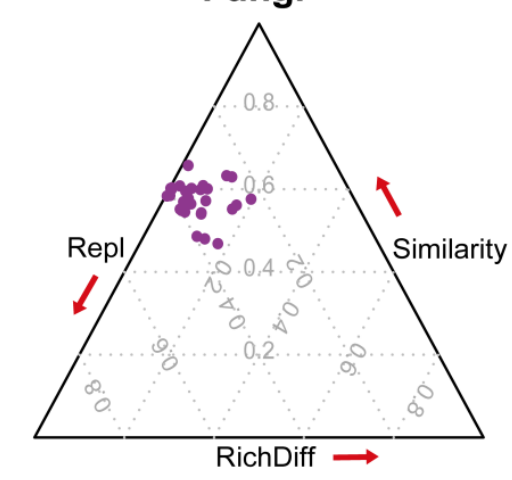

$\mathrm{S}=0.5676$, Repl $=0.3375$, RichDiff $=0.0947$ ( $n=30$ pairs of sites, within elevation)

Figure 3 Triangular plots of beta diversity comparisons (using Sørensen dissimilarity index) for bacterial and fungal communities among all sites (a, b) and among sites within elevation (c, d). Each point represents a pair of sites. Its position is determined by a triplet of values from the S (similarity), Repl (replacement) and RichDiff (richness difference) matrices; each triplet sums to 1 . Mean values of S, Repl and RichDiff are shown. 

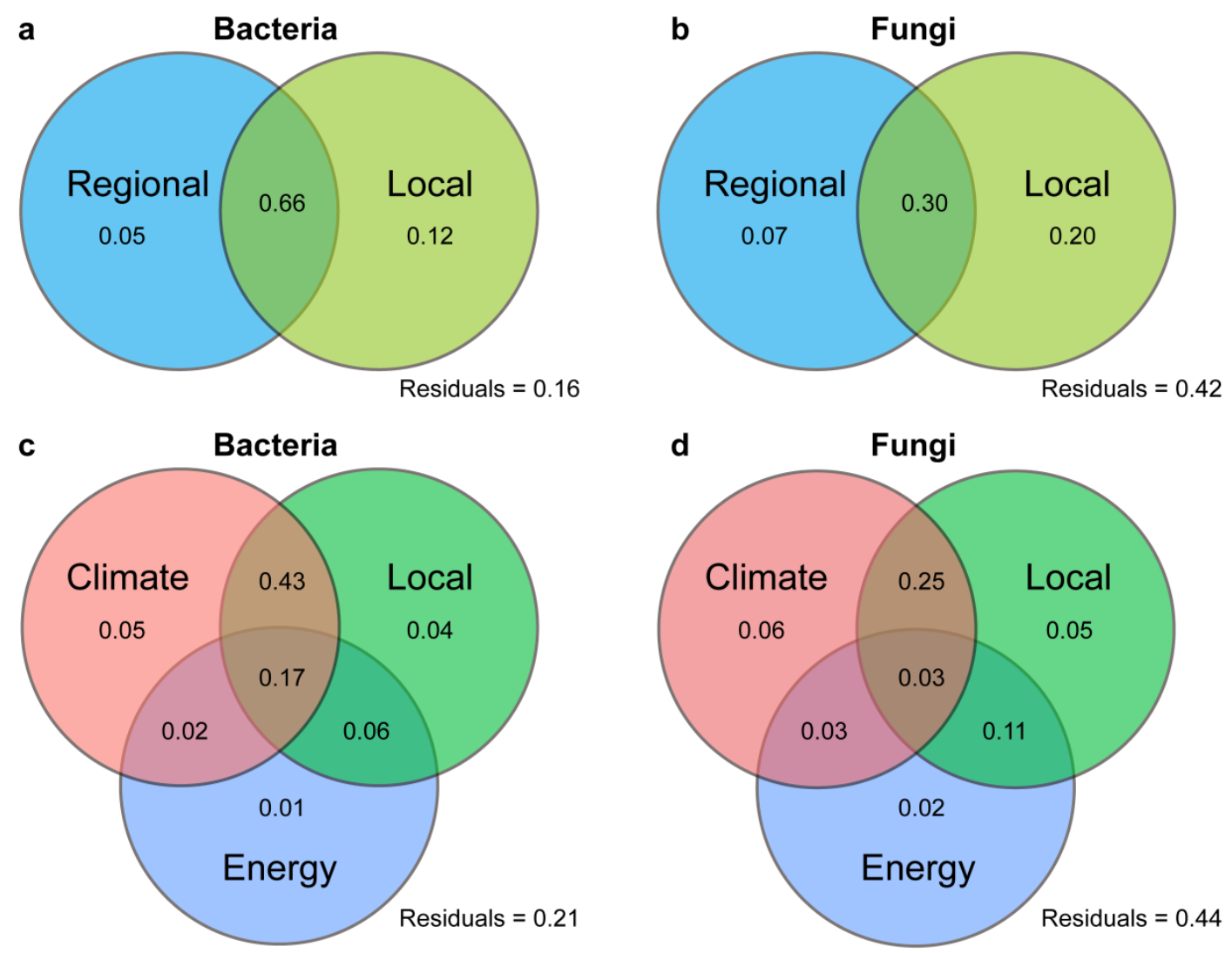

Figure 4 Results of variation partitioning analysis showing the percentages of explained variation for the composition of bacteria (a, c) and fungi (b, d). a. b. Variation was partitioned by regional factors (MAT, MAP and NDVI) and local factors $(\mathrm{pH}, \mathrm{TC}, \mathrm{TN}$ and $\mathrm{C} / \mathrm{N})$. c. d. Variation was partitioned by climate factors (MAT and MAP), energy factors (NDVI and TC) and local factors (pH, TN and C/N). MAT, mean annual temperature; MAP, mean annual precipitation; NDVI, normalized difference vegetation index; TC, total carbon; TN, total nitrogen. 
a

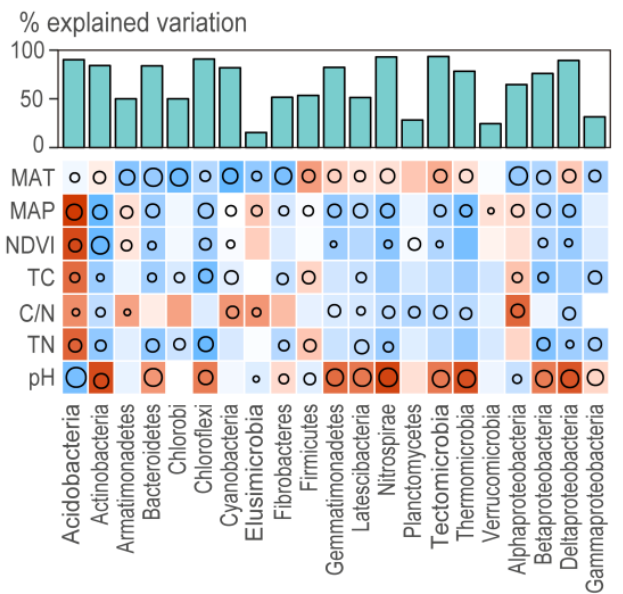

b $\quad$ Fungi

$\%$ explained variation

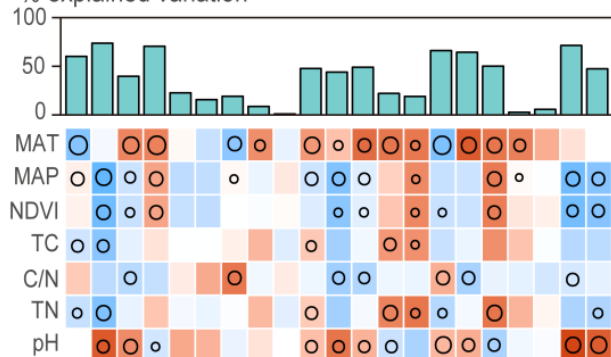

pH OOO OOOO OOO OO

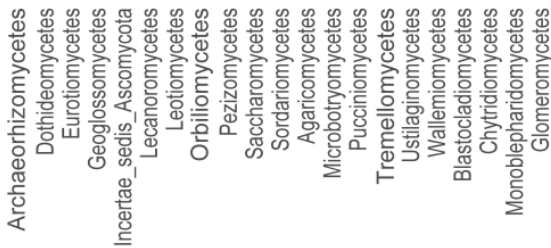

C

Predicted functional groups

$\%$ explained variation
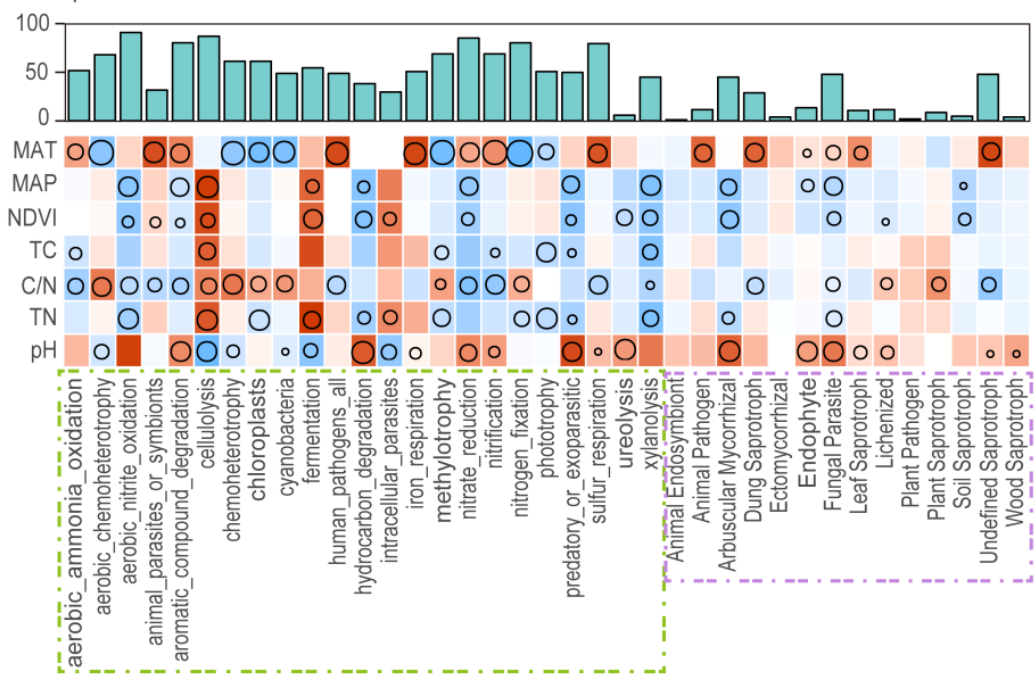

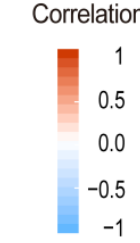

Importance (\%IncMSE)

- 5

○ 10

○ 15

○ 20

Figure 5 Correlation and best random forest model for relative abundance of major bacterial phyla (a, class for Proteobacteria), relative abundance of major fungal classes (b), relative abundance of predicted functional groups (c, green dash line means predicted functional groups based on bacterial taxa, purple dash line means predicted functional groups based on fungal taxa). For variable selection and estimating predictability, the random forest machine-learning algorithm was used. 
Circle size represents the variable importance (that is, decrease in the prediction accuracy (estimated with out-of-bag cross-validation)) as a result of the permutation of a given variable. Colors represent Spearman correlations. MAT, mean annual temperature; MAP, mean annual precipitation; NDVI, normalized difference vegetation index; TC, total carbon; TN, total nitrogen. 


\section{University Library}

\section{- M M N E R VA A gateway to Melbourne's research publications}

Minerva Access is the Institutional Repository of The University of Melbourne

Author/s:

Shen, C;Gunina, A;Luo, Y;Wang, J;He, J-Z;Kuzyakov, Y;Hemp, A;Classen, AT;Ge, Y

Title:

Contrasting patterns and drivers of soil bacterial and fungal diversity across a mountain gradient

Date:

2020-06-08

Citation:

Shen, C., Gunina, A., Luo, Y., Wang, J., He, J. -Z., Kuzyakov, Y., Hemp, A., Classen, A. T. \& $\mathrm{Ge}, \mathrm{Y}$. (2020). Contrasting patterns and drivers of soil bacterial and fungal diversity across a mountain gradient. ENVIRONMENTAL MICROBIOLOGY, 22 (8), pp.3287-3301. https:// doi.org/10.1111/1462-2920.15090.

Persistent Link:

http://hdl.handle.net/11343/275877 